\title{
FABRICATION OF AL ALLOY COMPOSITE REINFORCED WITH SILICON CARBIDE AND GRAPHITE THROUGH STIR CASTING PROCESS AND WEAR
}

\section{ANALYSIS}

\author{
Dr. K. SRIVIDYA ${ }^{1}$, CH. MOHAN SUMANTH ${ }^{2}$, J. SURENDRA ${ }^{3} \&$ V. SANKARARAO ${ }^{4}$ \\ ${ }^{1}$ Associate Professor, Department of Mechanical Engineering, P V P Siddhartha Institute of Technology, \\ Vijayawada, Andhra Pradesh, India \\ ${ }^{2,3}$ Assistant Professor, Department of Mechanical Engineering, P V P Siddhartha Institute of Technology, \\ Vijayawada, Andhra Pradesh, India \\ ${ }^{4}$ Assistant Professor, Department of Mechanical Engineering, Lakireddy Balireddy College of Engineering,
} Mylavaram, Andhra Pradesh, India

\begin{abstract}
Aluminum silicon carbide got wide range of applications in various sector, fields and in many industries. Aluminum matrix composites (AMCs) and Hybrid aluminum matrix composites (HAMCs) have become a great choice and various reinforcements had prospective meeting the criteria of recent aerospace and automobile industries. This aluminum is replacing some of the positions likesteels, wood, graphite etc. They are stronger, stiffer and they alsoact like heat sink which subtracts for power electronics. At present we are going to study the 6351 hybrid aluminum metal matrix composite which reinforced with graphite and silicon carbide. For this we took the method of stir casting. Although we have several methods are there for making Al-Sic composite but we preferred this technique for its simplicity and economical and thenfollowed by wear test on the material. So, as we wantdifferent types of properties when we conducted the wear test on AMCs (aluminum matrix composites) at different weight fractions of $2 \%, 4 \%, 6 \%$ and $8 \%$ of siliconcarbide and graphite which compared with Al 6351 alloy. It studies on tri-biological properties of the materials atdifferent composites. Lastly we found that if the weight fraction increases the wear properties are improved of graphite and silicon carbide in aluminum matrix.
\end{abstract}

KEYWORDS: Stir casting, Wear test, Al6351, Aluminum matrix composites (AMCs), Hybrid Aluminum matrix composites (HAMCs) \& Tri-Biological properties

Received: May 25, 2020; Accepted: Jun 15, 2020; Published: Jun 29, 2020; Paper Id.: IJMPERDJUN2020128

\section{INTRODUCTION}

Composites are also known as man made multi phase material. The composites are made from combination of two or more materials, they different physical and chemical properties. Composites are divided in to two types they are reinforcements and matrix. When composites are compared with any type of steel or cast irons and someother materials I tholds better capability and having high capacity whencompared withthem. Composites are developing veryfast in various types of fields likeaerospace, automobile, architecture, energy, sports, medical, etc in someother fields. But in aerospace it occupies mostly half of the materials (nearly 53\%) are prepared from composites. The composites structure is like layers it can take the maximum damage and it can also recover easily. Not only in aerospace in automobile also decreasing the weight and increasing the boosting experience like in various fields it changes everything. They have different type of applications are to choose whether they have to take matrix or 
reinforcements. Composites have the properties like light weight, strong, stiffer materials. There are other several methods to make composites but we only focus on stir casting method of aluminum silicon carbide composite. Sozhamannan [1] done stir casting process, which has been employed for producing discontinuous particle reinforced metal matrix composites for decades. Hashmi [2] studied combined high specific strength with good corrosion resistance, metal matrix composites (MMCs) are materials that are attractive for a large range of engineering applications. Thirumalai Kumaran [4] presented the influence of Boron Carbide (B4C) particles on the dry sliding wear behavior of aluminum matrix alloy (AA6351) - Silicon Carbide ( $\mathrm{SiC}$ ) composite - produced by the stir casting method is investigated. Zhang [5] studied the wear of journal bearings, consisting of cobalt-based Tribaloy T-800 bushings and carbide-coated 316L stainless steel (316L SS) sleeves, was evaluated in a molten zinc-aluminum alloy at different speeds and loads. Erol Feyzullahoğlu [6] investigated the aluminium-based alloys, nowadays, are developed to be used in high performance engine bearings. Francis Xavier [8] studied with an increase in the population and industrialization, a lot of valuable natural resources are depleted to prepare and manufacture products. Srividya[10] fabricated the siliconcarbide and graphite reinforced aluminum MMC by stir casting method and conducted wear test to check characteristics.

\section{PROCEDURE FOR FABRICATION OF COMPOSITE}

\section{Stir Casting Method}

Stiris one of the casting processes which include a mechanical stir rerintrducing form of vertex to a mix of reinforcement of the matrix material. In this method the metal matrix composites had adispersed phase to a molten metal. It is suitable for metal matrix composites due to its cost effectiveness and applicable for large amount of production and easier control of its composite structure. By using stirrer the reinforcement material is evenlydistributed only at somedesired conditions.

The metal matrix composites involve the dispersed phase form liquid state to a molten metal. There is an interfacial bonding between liquid matrixes to dispersed phase particles.However, the process does not have any type of theoretical explanation but itcan be proved experimentally.It has been experimentally found that when stirring the stirring speed is less than $700 \mathrm{rpm}$, an ineffective vortex is formed that leads to no dispersion of particles in the aluminium melt. When the speed is raised up to $800 \mathrm{rpm}$, there is occurrence of turbulence and spattering of melt. Time of stirring depends on the amount of reinforcement particles to be dispersed in the aluminium alloy melt. After the complete addition of reinforcements, stirring has been continued for 5 minutes for better distribution. The temperature of the melt is maintained at $700-800^{\circ} \mathrm{C}$ as the increase in the reinforcement particles amount increases the melt viscosity. 


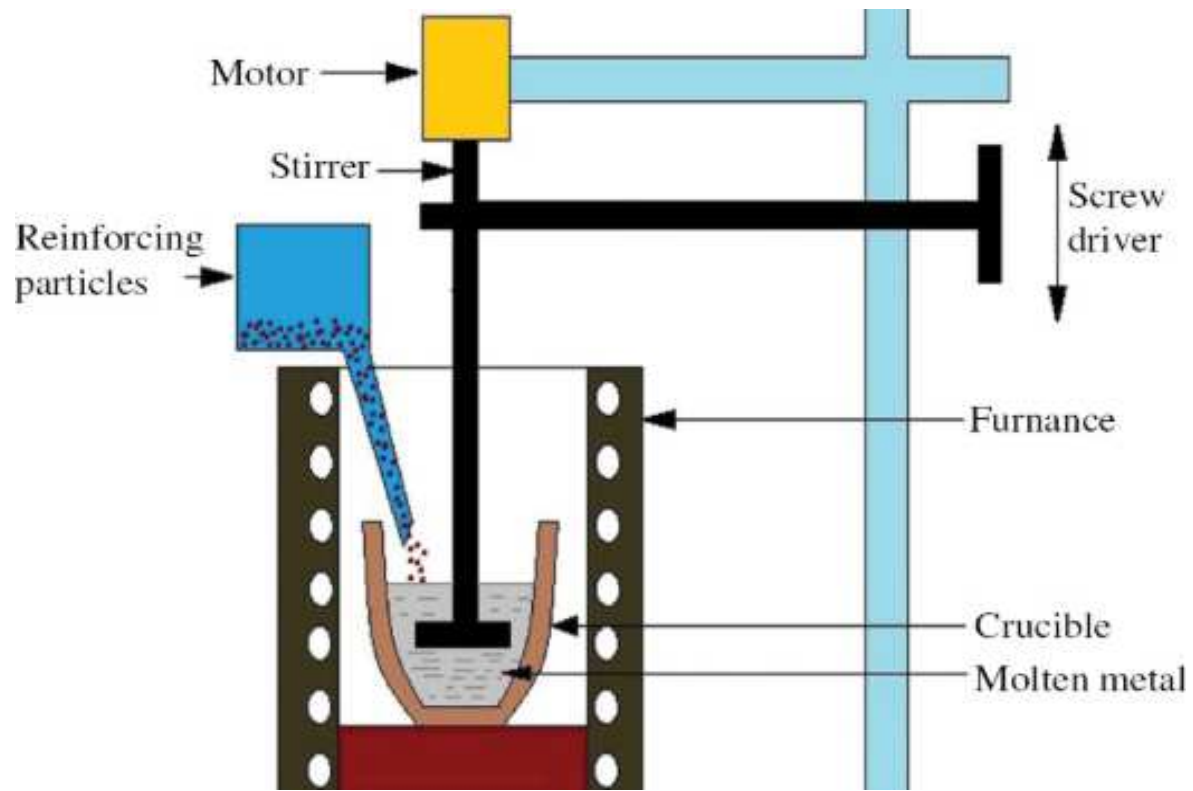

Figure 1: Stir Casting Experimental Setup.

The position of rotor must be $1 / 3$ of the height from the base of the die which takes place the formation of effective vortex. It involves the some of the steps. Firstly we have to melt the matrix material and then by using mechanical stirrermixing the moltenmetal and then feed to reinforcement material then we have to continuously stir the mixture (matrix material and reinforcement). Then pour the mixture in the mold. Aftersome time it solidifies. Aluminum siliconcarbide must be maintained at 600 to $800{ }^{\circ} \mathrm{C}$. Beforeadding the reinforcements it must be heated to a required temperature and must be taken out moisture content in the particles.

\section{Chemical Composition for AL 6351 Alloy}

The chemical composition of the aluminium 6351 alloy is tabulated below in table 1.

Table 1: Chemical Composition of the Aluminium 6351 Alloy

\begin{tabular}{|l|c|}
\hline \multicolumn{1}{|c|}{ Element } & Content (\%) \\
\hline Aluminium, $\mathrm{Al}$ & 97.8 \\
\hline Silicon, $\mathrm{Si}$ & 1 \\
\hline Manganese, $\mathrm{Mn}$ & 0.6 \\
\hline Magnesium, $\mathrm{Mg}$ & 0.6 \\
\hline
\end{tabular}

\section{Experimental Procedure for Wear Test}

Wear test is carried out to predict the wear performance and to investigate the wear mechanism. To check the wear performance we used pin-on-disc machine. Because, it is the best technique for checking the characteristics of Al 6351 alloy composites. The test was conducted under dry conditions atdifferent compositions. The pin was faced at counter of a disc (EN31 steel) rotator and the diameter of $60 \mathrm{~mm}$. In this test the sample pills are at dimension and length of $40 * 10$. Thesesamples are mounted to a pin holderwhichitwasloaded by adeadly weight after to the rotating disc. Now the test was conducted at different parameters which are sliding speed, sliding distance and loads. The samples were initially rubbed with emery paper to get fresh and flat surface followed to steel disc. At last it was cleaned with acetone and check weight which prior to each test. 


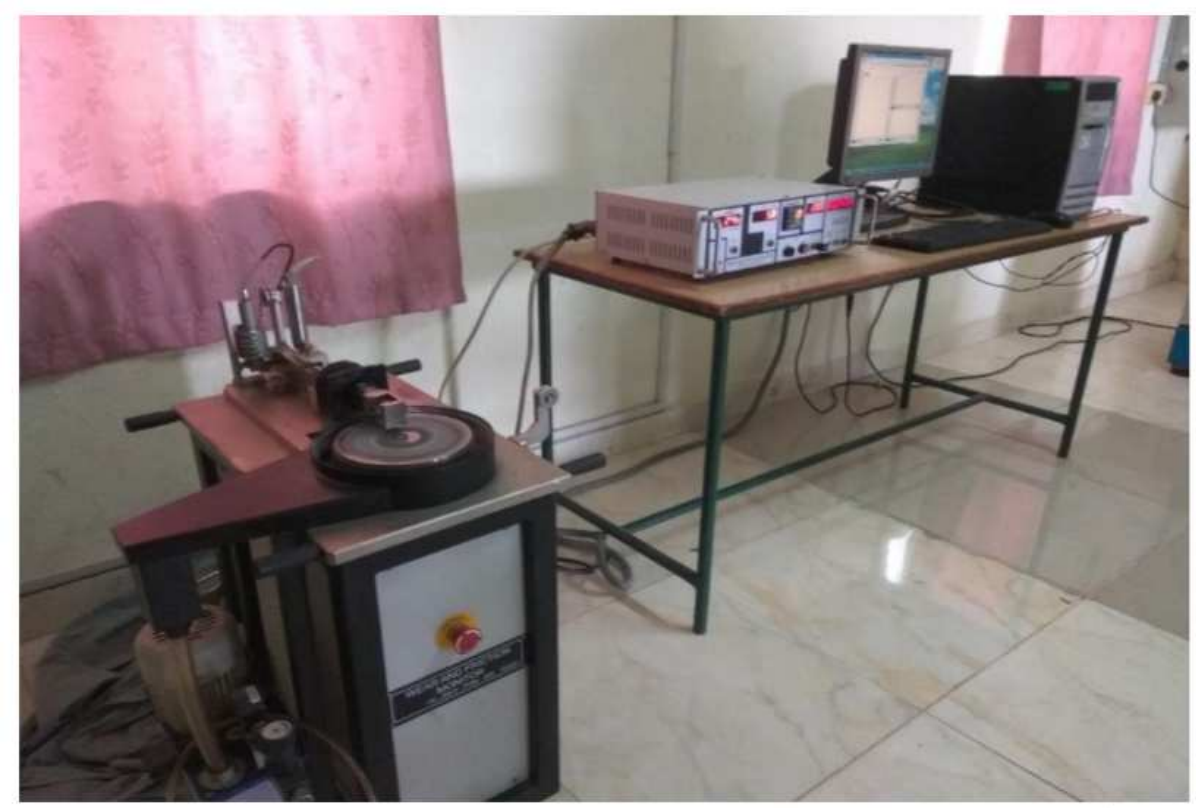

Figure 2: Pin-on-Disc Experimental setup.

After completing the test the height of the pin is measured and check with the initial height. By doing this technique the wear was calculated in terms of wear volume loss per unit sliding distance. In this test wekept the speed, distance and time is constant for entire experiment.

\section{RESULTS AND DISCUSSIONS}

\section{Wear Test}

Wear test is conducted successfully on pin-on-disc machine to find out the wear rate of Al 6351 alloy composites which combined with silicon carbide and graphite. The test was conducted on different weight of compositions.
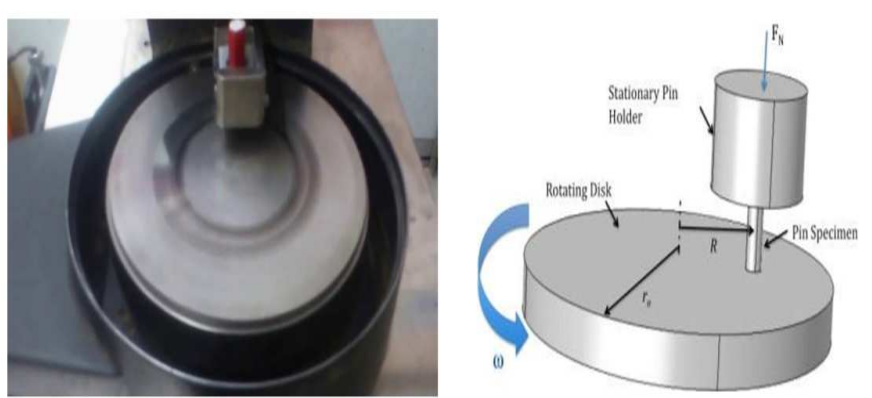

Figure 3: Pin-on-disc.

The different compositions are $2 \%, 4 \%, 6 \%$ and $8 \%$ which are fabricated with aluminumalloy, siliconcarbide and graphite with respectively.

\section{Test Procedure}

The pin was held against the counter face of a rotating disc (EN31 steel disc) where track diameter $60 \mathrm{~mm}$. The pin was loaded against the disc through a dead weight loading system the wear test for all specimens was conducted under the normal loads of 20,40 Newtons and the sliding velocity of 2 and $4 \mathrm{~m}$ per second wear test was carried out of total sliding 

through Stir Casting Process and Wear Analysis

distance of approximately 3000 metres under similar conditions as discussed above. The pill samples were $40 \mathrm{~mm}$ in length and $10 \mathrm{~mm}$ in diameter. The surface of the pin samples were slides using emery paper prior to test in order to ensure effective contact of fresh and flat surface with the steel disc. The samples and wear track were cleaned with acetone and weighed (up to an accuracy of 0.0001 gram using micro balance) prior to and after each test. The wear rate was calculated from the height loss technique and the expressed in terms of where volume loss per unit sliding distance. In this experiment, the test was conducted by the parameters of load, speed and distance. The parameters such as speed, distance, and time are kept constant for all experiment. The results of wear test of unreinforced alloy and MMC at different weight fractions of reinforcement shown below.

\section{CALCULATIONS FOR WEAR TEST}

Formulae: $\mathrm{V}=(\pi \mathrm{dR}) / 60$

$\mathrm{S}=\mathrm{V} * \mathrm{~T}$

Load=N (Newtons)

Speed=R (R.P.M)

Velocity $=\mathrm{V}(\mathrm{m} / \mathrm{s})$

Sliding Distance $=S$ (meters)

TrackDiameter $(\mathrm{d})=100 \mathrm{~mm}=0.1 \mathrm{~m}$

Time $=\mathrm{T}(\mathrm{sec})$

SampleCalculation:

Load $=10 \mathrm{~N}$

Speed $=150 \mathrm{rpm}$

Sliding Distance $=1500 \mathrm{~m}$

Then,

$\mathrm{V}=\pi \mathrm{dR} / 60$

$=(3.14 * 0.1 * 300) / 60$

$=1.57 \mathrm{~m} / \mathrm{sec}$

$\mathrm{S}=\mathrm{V} * \mathrm{~T}$

$\mathrm{T}=\mathrm{S} / \mathrm{V}$

$\mathrm{T}=1500 / 1.57$

$=955.41 \mathrm{sec}=15.92 \mathrm{~min}$.

\section{FORMULA}

Wear Rate $=$ WeightLoss $/$ (Density*Sliding Distance $)$ 
WeightLoss $=\Delta \mathrm{W}$

$=\mathrm{W} 1-\mathrm{W} 2$

W1=Weight of specimenbefore wear

W2=Weight of specimenafter wear

$\dot{\rho}=$ Density of specimen

$\mathrm{W}=\Delta \mathrm{w} /\left(\dot{\rho}^{*} \mathrm{~S}\right)$

SampleCalculations:

$\mathrm{W}=(0.01) /\left(2.7 * 10^{\wedge}-3 * 1000\right)$

$\mathrm{W}=0.0037 \mathrm{~mm}^{\wedge} 3 / \mathrm{m}$

\section{FORMULA}

Frictional Force $=\mathrm{F}$ (Newtons)

Coefficient of friction $=\mu$

$\mu=\mathrm{F} / \mathrm{N}$

\section{SampleCalculation}

$$
\begin{aligned}
\mathrm{F} & =7.5(\mathrm{~N}) \\
\mathrm{N} & =1 \mathrm{Kgf} \\
& =1 * 9.81 \mathrm{~N}=9.81 \mathrm{~N} \\
\mu & =7.5 / 9.81 \\
& =0.76
\end{aligned}
$$

The following tables 2-6 shows the values of wear test which tested on different compositions $(2 \%, 4 \%, 6 \%$ and $8 \%)$

Table 2: Al Alloy 6351 Pure

\begin{tabular}{|c|c|c|c|c|c|c|c|c|c|}
\hline Samples & $\begin{array}{c}\text { Load } \\
(\mathbf{K g f})\end{array}$ & $\begin{array}{c}\text { Sliding } \\
\text { velocity } \\
(\mathbf{m} / \mathbf{s})\end{array}$ & $\begin{array}{c}\text { Sliding } \\
\text { Speed } \\
(\mathbf{R . P . M})\end{array}$ & $\begin{array}{c}\text { Sliding } \\
\text { Distance } \\
(\mathbf{m})\end{array}$ & $\begin{array}{c}\text { Wear } \\
\text { rate } \\
(\mathbf{m m})^{\wedge} \mathbf{3}\end{array}$ & $\begin{array}{c}\text { Wear Rate } \\
(\mathbf{m m})^{\wedge} \mathbf{3 / m}\end{array}$ & $\begin{array}{c}\text { Frictional } \\
\text { force(N) }\end{array}$ & $\begin{array}{c}\text { COF } \\
(\boldsymbol{\mu})\end{array}$ & $\begin{array}{c}\text { Time } \\
(\mathbf{m i n})\end{array}$ \\
\hline 1 & 1 & 0.785 & 150 & 1000 & 276 & 0.87 & 7.5 & 0.76 & 21.23 \\
\hline 2 & 1 & 1.57 & 300 & 1500 & 280 & 0.9 & 7.0 & 0.71 & 16.32 \\
\hline 3 & 1 & 2.355 & 450 & 2000 & 281 & 0.98 & 5.7 & 0.58 & 14.15 \\
\hline 4 & 2 & 0.785 & 150 & 1500 & 340 & 0.97 & 9.9 & 0.5 & 21.23 \\
\hline 5 & 2 & 1.57 & 300 & 2000 & 365 & 0.99 & 5.7 & 0.29 & 16.32 \\
\hline 6 & 2 & 2.355 & 450 & 1000 & 399 & 0.9 & 10.8 & 0.55 & 14.15 \\
\hline 7 & 3 & 0.75 & 150 & 2000 & 414 & 0.9 & 5.9 & 0.2 & 21.23 \\
\hline 8 & 3 & 1.57 & 300 & 1000 & 433 & 0.87 & 10.2 & 0.34 & 16.32 \\
\hline 9 & 3 & 2.355 & 450 & 1500 & 447 & 0.97 & 4.0 & 0.13 & 14.15 \\
\hline
\end{tabular}


Table 3: Al Alloy 6351+2\% GRAPHITE+ 2\% Silicon Carbide

\begin{tabular}{|c|c|c|c|c|c|c|c|c|c|}
\hline Samples & $\begin{array}{c}\text { Load } \\
(\mathbf{K g f})\end{array}$ & $\begin{array}{c}\text { Sliding } \\
\text { velocity } \\
(\mathbf{m} / \mathbf{s})\end{array}$ & $\begin{array}{c}\text { Sliding } \\
\text { speed } \\
(\mathbf{R . P . M})\end{array}$ & $\begin{array}{c}\text { Sliding } \\
\mathbf{d i s t a n c e} \\
(\mathbf{m})\end{array}$ & $\begin{array}{c}\text { Wear } \\
\mathbf{r a t e} \\
(\mathbf{m m})^{\wedge} \mathbf{3}\end{array}$ & $\begin{array}{c}\text { Wear rate } \\
(\mathbf{m m})^{\wedge} \mathbf{3 / m}\end{array}$ & $\begin{array}{c}\text { Frictional } \\
\text { force(N) }\end{array}$ & $\begin{array}{c}\text { COF } \\
(\boldsymbol{\mu})\end{array}$ & $\begin{array}{c}\text { Time } \\
(\mathbf{m i n})\end{array}$ \\
\hline 1 & 1 & 0.785 & 150 & 1000 & 230 & 0.0041 & 2.6 & 0.27 & 21.23 \\
\hline 2 & 1 & 1.57 & 300 & 1500 & 234 & 0.0041 & 2.6 & 0.27 & 16.32 \\
\hline 3 & 1 & 2.355 & 450 & 2000 & 247 & 0.0041 & 2.6 & 0.27 & 14.15 \\
\hline 4 & 2 & 0.785 & 150 & 1500 & 312 & 0.005 & 5.4 & 0.28 & 21.23 \\
\hline 5 & 2 & 1.57 & 300 & 2000 & 276 & 0.0056 & 5.4 & 0.28 & 16.32 \\
\hline 6 & 2 & 2.355 & 450 & 1000 & 279 & 0.0055 & 5.2 & 0.27 & 14.15 \\
\hline 7 & 3 & 0.75 & 150 & 2000 & 312 & 0.006 & 8.8 & 0.30 & 21.23 \\
\hline 8 & 3 & 1.57 & 300 & 1000 & 315 & 0.0056 & 8.8 & 0.30 & 16.32 \\
\hline 9 & 3 & 2.355 & 450 & 1500 & 340 & 0.0059 & 8.5 & 0.29 & 14.15 \\
\hline
\end{tabular}

Table 4: Al Alloy 6351+4\% Graphite+ 4\% Silicon Carbide

\begin{tabular}{|c|c|c|c|c|c|c|c|c|c|}
\hline Samples & $\begin{array}{c}\text { Load } \\
(\mathbf{K g f})\end{array}$ & $\begin{array}{c}\text { Sliding } \\
\text { velocity } \\
(\mathbf{m} / \mathbf{s})\end{array}$ & $\begin{array}{c}\text { Sliding } \\
\text { speed } \\
(\mathbf{R . P . M})\end{array}$ & $\begin{array}{c}\text { Sliding } \\
\mathbf{d i s t a n c e} \\
(\mathbf{m})\end{array}$ & $\begin{array}{c}\text { Wear } \\
\text { rate } \\
(\mathbf{m m})^{\wedge} \mathbf{3}\end{array}$ & $\begin{array}{c}\text { Wear rate } \\
(\mathbf{m m})^{\wedge} \mathbf{3} / \mathbf{m}\end{array}$ & $\begin{array}{c}\text { Frictional } \\
\text { force(N) }\end{array}$ & $\begin{array}{c}\mathbf{C O F} \\
(\boldsymbol{\mu})\end{array}$ & $\begin{array}{c}\text { Time } \\
(\mathbf{m i n})\end{array}$ \\
\hline 1 & 1 & 0.785 & 150 & 1000 & 100 & 0.003 & 2.1 & 0.21 & 21.23 \\
\hline 2 & 1 & 1.57 & 300 & 1500 & 121 & 0.0032 & 2.1 & 0.21 & 16.32 \\
\hline 3 & 1 & 2.355 & 450 & 2000 & 168 & 0.0033 & 2.2 & 0.22 & 14.15 \\
\hline 4 & 2 & 0.785 & 150 & 1500 & 111 & 0.0032 & 7.3 & 0.24 & 21.23 \\
\hline 5 & 2 & 1.57 & 300 & 2000 & 139 & 0.0030 & 5.0 & 0.25 & 16.32 \\
\hline 6 & 2 & 2.355 & 450 & 1000 & 168 & 0.003 & 4.8 & 0.24 & 14.15 \\
\hline 7 & 3 & 0.75 & 150 & 2000 & 187 & 0.0037 & 8.0 & 0.27 & 21.23 \\
\hline 8 & 3 & 1.57 & 300 & 1000 & 202 & 0.0033 & 2.7 & 0.27 & 16.32 \\
\hline 9 & 3 & 2.355 & 450 & 1500 & 205 & 0.0037 & 2.7 & 0.27 & 14.15 \\
\hline
\end{tabular}

Table 5: Al Alloy 6351+6\% Graphite+ 6\% Silicon Carbide

\begin{tabular}{|c|c|c|c|c|c|c|c|c|c|}
\hline Samples & $\begin{array}{c}\text { Load } \\
(\mathbf{K g f})\end{array}$ & $\begin{array}{c}\text { Sliding } \\
\text { velocity } \\
(\mathbf{m} / \mathbf{s})\end{array}$ & $\begin{array}{c}\text { Sliding } \\
\text { speed } \\
(\mathbf{R . P . M})\end{array}$ & $\begin{array}{c}\text { Sliding } \\
\mathbf{d i s t a n c e} \\
(\mathbf{m})\end{array}$ & $\begin{array}{c}\text { Wear } \\
\mathbf{r a t e} \\
(\mathbf{m m})^{\wedge} \mathbf{3}\end{array}$ & $\begin{array}{c}\text { Wear rate } \\
(\mathbf{m m})^{\wedge} \mathbf{3 / m}\end{array}$ & $\begin{array}{c}\text { Frictional } \\
\text { force(N) }\end{array}$ & $\begin{array}{c}\text { COF } \\
(\boldsymbol{\mu})\end{array}$ & $\begin{array}{c}\text { Time } \\
(\mathbf{m i n})\end{array}$ \\
\hline 1 & 1 & 0.785 & 150 & 1000 & 59 & 0.002 & 0.09 & 0.01 & 21.23 \\
\hline 2 & 1 & 1.57 & 300 & 1500 & 76 & 0.0022 & 0.294 & 0.03 & 16.32 \\
\hline 3 & 1 & 2.355 & 450 & 2000 & 79 & 0.0024 & 0.294 & 0.03 & 14.15 \\
\hline 4 & 2 & 0.785 & 150 & 1500 & 60 & 0.0025 & 2.74 & 0.14 & 21.23 \\
\hline 5 & 2 & 1.57 & 300 & 2000 & 81 & 0.0027 & 2.74 & 0.14 & 16.32 \\
\hline 6 & 2 & 2.355 & 450 & 1000 & 106 & 0.002 & 1.07 & 0.11 & 14.15 \\
\hline 7 & 3 & 0.75 & 150 & 2000 & 96 & 0.0027 & 5.59 & 0.19 & 21.23 \\
\hline 8 & 3 & 1.57 & 300 & 1000 & 100 & 0.002 & 5.59 & 0.19 & 16.32 \\
\hline 9 & 3 & 2.355 & 450 & 1500 & 110 & 0.0024 & 4.70 & 0.16 & 14.15 \\
\hline
\end{tabular}

Table 6: Al Alloy 6351+8\% Graphite+ $8 \%$ Silicon Carbide

\begin{tabular}{|c|c|c|c|c|c|c|c|c|c|}
\hline Samples & $\begin{array}{c}\text { Load } \\
(\mathbf{K g f})\end{array}$ & $\begin{array}{c}\text { Sliding } \\
\text { velocity } \\
(\mathbf{m} / \mathbf{s})\end{array}$ & $\begin{array}{c}\text { Sliding } \\
\text { speed } \\
(\mathbf{R . P . M})\end{array}$ & $\begin{array}{c}\text { Sliding } \\
\mathbf{d i s t a n c e} \\
(\mathbf{m})\end{array}$ & $\begin{array}{c}\text { Wear } \\
\mathbf{r a t e} \\
(\mathbf{m m})^{\wedge} \mathbf{3}\end{array}$ & $\begin{array}{c}\text { Wear rate } \\
(\mathbf{m m})^{\wedge} \mathbf{3 / m}\end{array}$ & $\begin{array}{c}\text { Frictional } \\
\text { force(N) }\end{array}$ & $\begin{array}{c}\text { COF } \\
(\boldsymbol{\mu})\end{array}$ & $\begin{array}{c}\text { Time } \\
(\mathbf{m i n})\end{array}$ \\
\hline 1 & 1 & 0.785 & 150 & 1000 & 122 & 0.056 & 2.06 & 0.21 & 21.23 \\
\hline 2 & 1 & 1.57 & 300 & 1500 & 160 & 0.06 & 2.06 & 0.21 & 16.32 \\
\hline 3 & 1 & 2.355 & 450 & 2000 & 194 & 0.0062 & 2.15 & 0.22 & 14.15 \\
\hline 4 & 2 & 0.785 & 150 & 1500 & 137 & 0.0083 & 4.12 & 0.21 & 21.23 \\
\hline 5 & 2 & 1.57 & 300 & 2000 & 181 & 0.0083 & 4.31 & 0.22 & 16.32 \\
\hline 6 & 2 & 2.355 & 450 & 1000 & 202 & 0.0074 & 4.12 & 0.21 & 14.15 \\
\hline 7 & 3 & 0.75 & 150 & 2000 & 205 & 0.06 & 8.53 & 0.29 & 21.23 \\
\hline 8 & 3 & 1.57 & 300 & 1000 & 243 & 0.012 & 8.24 & 0.28 & 16.32 \\
\hline 9 & 3 & 2.355 & 450 & 1500 & 247 & 0.0187 & 7.06 & 0.24 & 14.15 \\
\hline
\end{tabular}




\section{CONCLUSIONS}

As we observe the results of aluminum matrix composites is reinforced with siliconcarbide and graphite and at different compositions are $2 \%, 4 \%, 6 \%$ and $8 \%$. The above process done in stir casting method and these results were done by pin on-disc which to know the wear characteristics on the composites. As we see that the wear performance of the $\mathrm{Al}$ composite which reinforced with siliconcarbide and graphite is increased and if we observe the last composite with the weight of $8 \%$ is showed maximum wear performance. When the increase of composition of siliconcarbide and graphite there is increase of composition concentration, decrease in density. In stir casting process the stirring speed, time and distance are important parameters. So these types of composites are chosen for various fields and in some industries.

\section{ACKNOWLEDGEMENTS}

We would like to thank the management of Siddhartha Academy of general and technical education [SAGTE], Convener of PVP Siddhartha Institute of technology, Principal of PVP Siddhartha Institute of technology for supporting us to carry out this work academically and financially.

\section{REFERENCES}

1. Sozhamannan, G. G., Prabu S Balasivanandha. and Venkatagalapathy, V.S.K. (2012). Effect of processing parameters on metal matrix composites:stir casing process. Journal of Surface Engineered Materials and Advanced Technology. 2, 11-15.

2. Hashim, J., Looney, L. and Hashmi, M.S.J. (1999). Metal matrix composites production by the stir casting method. Journal of materials processing technology. 92, 1-7.

3. YADAV, GR KRISHNA PRASAD, M. VISHNU VARDHAN REDDY, and P. RAJENDRA PRASAD. "FABRICATION AND STRUCTURAL ANALYSIS OF ALUMINIUM ALLOY (LM25) REINFORCED WITH SILICON CARBIDE AND GRAPHITE PARTICULATE." International Journal of Mechanical and Production Engineering Research and Development (IJMPERD) 8. 2, Apr 2018, 1-10

4. Thirumalai Kumaran, S., Uthayakumar, M., Aravindan, S. and Rajesh, S. (2016). Dry sliding wear behaviour of dictionary and B4C -reinforced AA6351 metal matrix composite produced by stir casting process Proceedings of the Institution of Mechanical Engineers. Part L: Journal of Materials: Design and Applications 230 (2), 484-491.

5. Zhang, K. (2005). Effects of test conditions on the tribological behaviour of a journal bearing in molten zinc. Wear. 259, 12481253.

6. Erol Feyzullahoğlu., Nehir Şakiroglu. (2010). The wear of aluminium-based journal bearing materials under lubrication. Materials and Design (1980-2015). 31(5), 2532-2539.

7. Shankar, MC Gowri, et al. "Experimental investigation on silicon carbide reinforced Duralumin based mmc produced by cold compacting." International Journal of Mechanical and Production Engineering Research and Development 9.2 (2019): 507 524.

8. Francis Xavier, L. and Paramadham Suresh. (2016). Wear behaviour of aluminum metal matrix composite prepared from industrial waste.The scientific world journal. Article ID 6538345, 1-9.

9. Suresh, S., G. Harinathgowd, and MLS DEVA KUMAR. "Mechanical behavior of Al 7075 reinforced with AL2O3 And SiC Nano particles Fabricated by Stir Casting Method." International Journal of Mechanical and Production Engineering Research and Development (IJMPERD) ISSN (P): 2249-6890.

10. Srividya, K., Anusha, P., Kavitha, E. and Nagaswapnasri, M. (2019). Fabrication of silicon carbide and graphite reinforced 

through Stir Casting Process and Wear Analysis

aluminium MMC by stir casting and characterization by wear test. International journal of innovative technology and Exploring Engineering. 8, 4033-4038.

11. Saha, Nandini, et al. "Comparative Study of IV-Characteristics of PIN Diode at Different Doping Concentrations for Different Semiconductor Materials Using TCAD." International Journal of Electronics and Communication Engineering (IJECE) 4.6 (2015): 1-8. 
